\title{
Sadness as perceived by Indonesian male and female adolescents
}

Putri, Adelia Khrisna $\triangle($ (adelputri08@gmail.com)

Center for Indigenous \& Cultural Psychology, Faculty of Psychology, Universitas Gadjah Mada, Indonesia

Prawitasari, Johana Endang (jepe@ygy.centrin.net.id)

Center for Indigenous \& Cultural Psychology, Faculty of Psychology, Universitas Gadjah Mada, Indonesia

Hakim, Moh. Abdul (hakimpsi@yahoo.com)

Center for Indigenous \& Cultural Psychology, Faculty of Psychology, Universitas Gadjah Mada, Indonesia

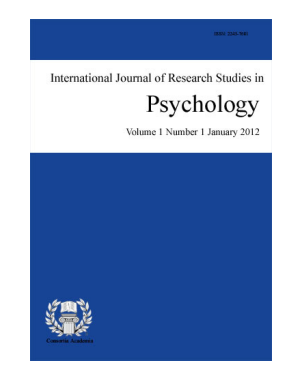

ISSN: $2243-7681$ Online ISSN: 2243-769X

OPEN ACCESS

Yuniarti, Kwartarini W. (kwartarini yuniarti@yahoo.com)

Center for Indigenous \& Cultural Psychology, Faculty of Psychology, Universitas Gadjah Mada, Indonesia

Kim, Uichol (uicholk@chol.com)

School of Business Administration, Inha University, Korea

Received: 8 August $2011 \quad$ Revised: 8 September $2011 \quad$ Accepted: 9 September 2011 $\begin{array}{ll}\text { Available Online: } 10 \text { September } 2011 & \text { DOI: } 10.5861 / \text { ijrsp.2012.v1i1.22 }\end{array}$

\section{Abstract}

Adolescence is a transition phase filled with doubt and instability. During these transitions, some obstacles are often perceived as more intense and frequently cause adolescents to feel sad. This study was aimed to identify how male and female adolescents perceived sadness. A total number of 461 students, 273 females and 188 males, all of whom were high school students in Yogyakarta, completed an open-ended questionnaire, developed by Kim and Park (2006). The data was categorized, open-coded, axial-coded, and later cross-tabulated. Results demonstrated that females perceive negative moments as a life-lesson $(30.4 \%)$, self reflection (13.9\%), disruption (13.6\%), life's obstacles (8.1\%), motivation (6.6\%), memorable moments $(6.6 \%)$, and lastly as a spiritual-lesson $(2.6 \%)$. While males view sadness as a life lesson (22.9\%), disruption (15.4\%), self-reflection (11.2\%), motivation (9.6\%), memorable moments (5.9\%), life's obstacles (5.3\%), and lastly as a spiritual lesson (3.2\%). This result was later divided into two types of perception, the positive approach, containing life lesson, self-reflection, motivation, and spiritual lesson, and the negative approach, which are sadness as disruption, memorable moments, and life's obstacles. This study concludes that both Indonesian male and female adolescent mainly took a positive perception on sadness as a life lesson, with only $27 \%$ of them viewing it as negative.

Keywords: sadness; Indonesian adolescents; indigenous psychology; quantitative study; gender differences 


\section{Sadness as perceived by Indonesian male and female adolescents}

\section{Introduction}

As adolescence are a time of great change and often a stormy time of developmental turmoil and conflicting emotional states, the sense of new-found independence, often cause adolescents to plunge into spirals of emotional turbulence (Karnani \& Pomm, 2006). Emotions serve the function of regulating interactions between individuals and their environment, organizing and motivating goal-driven behavior (Campos, Campus, \& Barrett, 1989; Sullivan, Helms, Kliewer, \& Goodman, 2008). It is accompanied by, having a sense of understanding of what is currently happening, and feeling able to predict what is to come. In contrast, other emotions are characterized by feelings of uncertainty, confusion of what is happening, and feeling unsure about what will happen next (Ellsworth \& Smith, 1988; Brinol, Barden, \& Petty, 2007). Emotional conflicts such as anger and sadness, is one of the strongest emotions that take part in the adolescents' life. The function of sadness is to regulate as well as communicate the need for social support (Sullivan et al., 2008).

Sadness as well as any negative emotion is triggered by the appearance of stress, which is the basis of every psychological distress (Durand \& Barlow, 2006). Disregarded sadness could very much turn into a state of depression, as they are very highly correlated to one another, as proven in a self-report study on children, adolescent, as well as college students (Kasch, Rottenberg, Arnow, \& Gotlib, 2002). The significant impact of sadness on the psychological wellbeing of adolescents can also be seen by the fact that feeling sad, and appearing sad or tearful serves as two of the criteria for Major Depressive Episode in the Diagnostic and Statistical Manual of Mental Disorders-IV (DSM-IV); the manual published by the American Psychiatric Association (Chaplin, 2006). Based on these studies it can be seen that sadness is one of the strongest negative emotion that are used to regulate the social need and behavior of a person, and can easily turn into depression.

In Indonesia, stereotypes on gender-based emotional expression as well as social roles are still very high. Stereotypes abound that sadness is a feminine emotion and anger is a masculine emotion (Brody \& Hall, 2000; Fischer, Rodriguez Mosquera, Van Vianen, \& Manstead, 2004; Tiedens, 2001; Rivers, Brackett, Katulak, \& Salovey, 2007). Thus, the way a boy should behave as well as how girls behave is very distinct. The types of job that they do are also, often, based on the stereotypes of how males are expectedly stronger than girls. Boys tend to display more aggressive, antisocial, delinquent or externalizing behaviors, whereas girls present more anxious-depressive or internalizing problems (Garaigordobil, Maganto, Perez, \& Sansinenea, 2009). These were influenced by their parents, community, and especially by their social groups. Parents socialize children into the specific attitudes and values endorsed by their cultural community through daily conversations. One such value is the expression of emotion that conforms to culturally prescribed gender roles (Aldrich \& Tenenbaum, 2006). Aldrich and Tenenbaum (2006) found that girls tend to display more depressive behavior because the way her mother talked to her, involved many sad emotions and attitudes when facing problems. This was modeled by the child and thus follows a gender stereotype that women are more emotional and are less able to cope well. Children's social groups also comprise sex-distinctive subcultures that may influence behavior along gender lines strengthening the concept of sex-differences that they learnt at the beginning (Maccoby, 2002; Parrish \& Zeman, 2009). Thus it is seen that there is a culturally gender-specific expectation between males and females that shapes their early perspective of themselves.

In conforming to these gender-specific expectations, over time, it can cause adolescents to be trapped in emotional reactions that will also be stereotypical. Such responses could have negative implications for people's psychological well-being (Fischer, 2000). For example, if women come to view their own emotional experiences as filled with sadness, a low status emotion, it may have implications for their sense of power and self-efficacy (Algoe, Buswell, \& DeLamater, 2000; Tiedens, Ellsworth, \& Mesquita, 2000; Plant, Kristen, \& Smith, 2004). On the other hand when males come to view their emotional experiences as something not worth showing, they may 
be more prone in showing aggressive behavior and creating more burdens from unfinished business. This illustrates the different perspective of culturally gendered-expectations, as well as stereotypes. Few studies have touched the notion of adolescents' perception on sadness, thus it becomes a valuable contribution to have data on Indonesian adolescents' perception. Further, understanding adolescents' perception on sadness help create a prevention toward the severity of their sadness level.

\section{Indigenous psychology}

Indigenous psychology, according to Kim and Berry (1993) is defined as "the scientific study of human behavior or mind that is native, that is not transported from other regions, and that is designed for its people". It challenges the concept of universality upon psychological theories (Kim \& Park, 2006). The notion of general psychology is to create a broad and universal theory, while indigenous psychology focuses on understanding psychology in the social context of each nation (Kim \& Park, 2006). Not only does it try to explore people as a community, it also focuses on the discovery of self for each individuals. The concept of understanding people is firstly done by understanding ourselves and thus indigenous psychology tries to explore a person's self concept of himself within their cultural context, family, and many others. For these reasons, the aim of indigenous psychology is to create a universally structured approach in understanding the people in their context.

\section{Methodology}

This study was done by using an indigenous approach, which emphasizes the study on the behavior and thoughts of indigenous people (Kim \& Berry, 1993). It revolves on the discovery of certain occurrence within the context of its culture.

\subsection{Participant}

The participants consist of 461 high school students in Yogyakarta between the ages of 14-18 years old. The subjects consist of 273 females and 188 males.

\subsection{Data collection}

The procedure of this study was firstly done by posing the question of "what is the meaning behind your sad moments". The question was based on an open-ended question developed by Kim and Park (2006), which allows the participants to explore their answers as the questions have no definite answer. The responses of those questions were later categorized based on keywords, and later put in themes, by at least three raters. Next, the categorized responses were open-coded by large categories and small categories, which were given numbers in ascending orders. These categories were used as the basis of descriptive analysis which was later cross tabulated with the respondents' gender.

\section{Results}

Based on the categorization of responses from 461 respondents (male: 188, female: 273), 7 categories appeared. The highest perception on sadness made by Indonesian adolescents is as a Life lesson (27.3\%). The second highest way to perceive sadness is by viewing it as a disruption (14.3\%) whilst the third category is to take it as a way of self-reflection (12.8\%). The remaining categories showed that Indonesian adolescents also view sadness as a form of motivation, life's obstacles, memorable moment, and lastly as a spiritual lesson. The order of which these categories were mentioned described the ranks from the highest to the lowest responses made by the respondent.

The researcher only focuses on these 7 categories, while the remaining categories containing $27.1 \%$ is not included in this discussion. The category of "Others" containing blank, irrelevant answer, meaningless, are not included in these categories. An important aspect that must be accounted for is that these main categories are 
Putri, A. K., Prawitasari, J. E., Hakim, M. A., Yuniarti, K. W., \& Kim, U.

formed by smaller categories. These categories can be seen in the figure 1 and 2 , and table 1 .

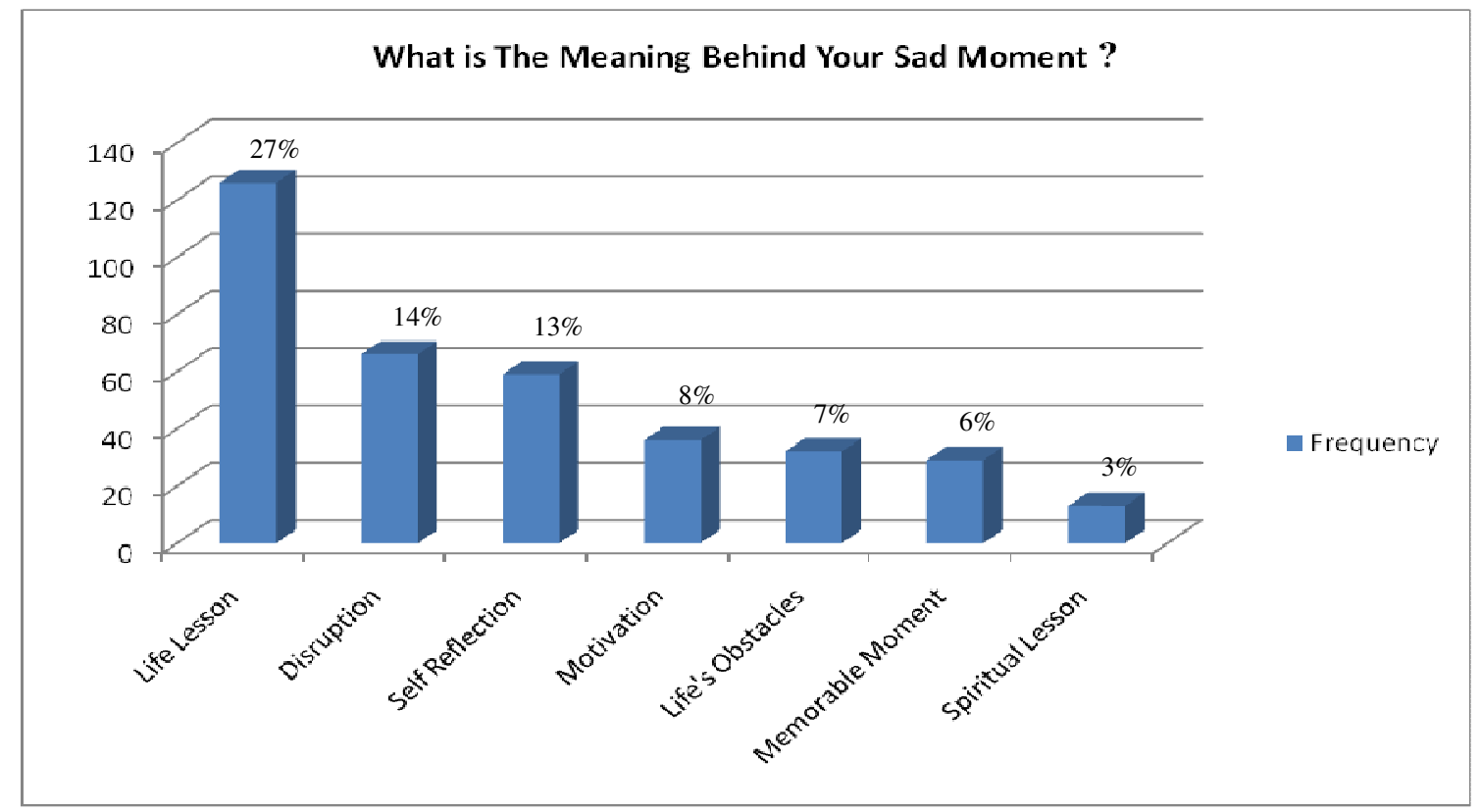

Figure 1. Graphical view of the sadness categories

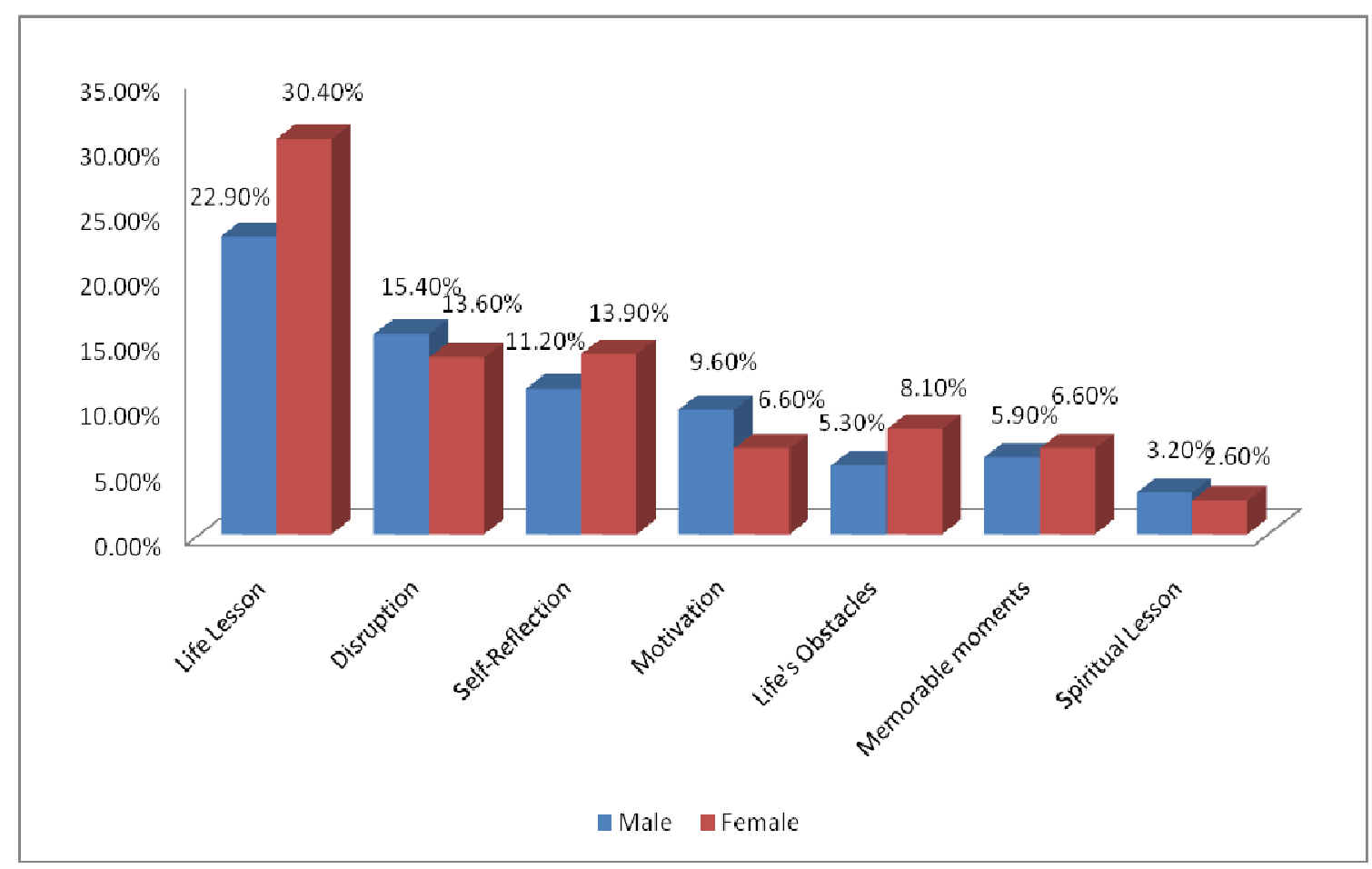

Figure 2. Gender comparison of the sadness categories 
Table 1

Sadness categories

\begin{tabular}{|c|c|c|c|}
\hline Category & Male & Female & Total \\
\hline 1. Life-Lesson & $43^{1}(22.9)^{2}$ & $84(30.5)$ & $127(27.7)$ \\
\hline Life-lesson & $20(10.6)$ & $31(11.4)$ & $51(11.1)$ \\
\hline Life-experience & $6(3.2)$ & $16(5.5)$ & $22(4.8)$ \\
\hline Finds meaning in life relatedness & $6(3.2)$ & $4(1.5)$ & $10(2.2)$ \\
\hline Life disparity & $2(1.1)$ & $9(3.3)$ & $11(2.4)$ \\
\hline Accept reality & $2(1.1)$ & $4(1.5)$ & $6(1.3)$ \\
\hline Valuable lesson & $7(3.7)$ & $20(7.3)$ & $27(5.9)$ \\
\hline 2. Disruption & $29(15.4)$ & 37 (13.7) & $66(17.8)$ \\
\hline Annoying & $5(2.7)$ & $9(3.3)$ & $14(3.0)$ \\
\hline Hurt & $16(8.5)$ & $16(5.9)$ & $32(6.9)$ \\
\hline Diminishing spirit & $6(3.2)$ & $7(2.6)$ & $13(2.8)$ \\
\hline Causes disturbance & $1(0.5)$ & $1(0.4)$ & $2(4.0)$ \\
\hline Causes loneliness & $1(0.5)$ & $4(1.5)$ & $5(1.1)$ \\
\hline 3. Self-reflection & $21(11.2)$ & $37(\mathbf{1 3 . 5})$ & $58(12.6)$ \\
\hline An awareness to be careful & $4(2.1)$ & $8(2.9)$ & $12(2.6)$ \\
\hline Self-awareness & $3(1.6)$ & $9(3.3)$ & $12(2.6)$ \\
\hline Self-improvement & $12(6.4)$ & $12(4.4)$ & $24(5.2)$ \\
\hline An awareness of self-relation & $2(1.1)$ & $8(2.9)$ & $10(2.2)$ \\
\hline 4. Motivation & $18(9.6)$ & $18(6.6)$ & $36(7.8)$ \\
\hline New motivation & $13(6.9)$ & $13(4.8)$ & $26(5.6)$ \\
\hline Stronger/tougher & $5(2.7)$ & $5(1.8)$ & $10(2.2)$ \\
\hline 5. Life's obstacles & $10(5.4)$ & $22(8.1)$ & $32(6.9)$ \\
\hline Losing someone & $1(0.5)$ & $7(2.6)$ & $8(1.7)$ \\
\hline Pressures of life & $2(1.1)$ & $4(1.5)$ & $6(1.3)$ \\
\hline Life's obstacles & $5(2.7)$ & $8(2.9)$ & $13(2.8)$ \\
\hline Failures & $2(1.1)$ & $3(1.1)$ & $5(1.1)$ \\
\hline 6. Memorable moments & $12(5.8)$ & $18(6.6)$ & $29(6.8)$ \\
\hline Very meaningful & $9(4.8)$ & $12(4.4)$ & $21(4.6)$ \\
\hline Unforgettable moments & $2(0.5)$ & $5(1.8)$ & $6(1.3)$ \\
\hline Unexpected moments & $1(0.5)$ & $1(0.4)$ & $2(0.9)$ \\
\hline 7. Spiritual-lessons & $6(3.2)$ & $7(2.5)$ & $13(2.9)$ \\
\hline Learns sincerity & $2(1.1)$ & $2(0.7)$ & $4(0.9)$ \\
\hline Spiritual & $4(2.1)$ & $5(1.8)$ & $9(2.0)$ \\
\hline 8. Others & $49(26.6)$ & $50(18.3)$ & $100(21.7)$ \\
\hline Irrelevant & $17(9.6)$ & $23(8.4)$ & $41(8.9)$ \\
\hline Meaningless & $12(6.4)$ & $14(5.1)$ & $26(5.6)$ \\
\hline Blank & $20(10.6)$ & $13(4.8)$ & $33(7.2)$ \\
\hline Total & $188(100)$ & $273(100)$ & $461(100)$ \\
\hline
\end{tabular}

Note. ${ }^{1}$ Frequency response. ${ }^{2}$ Percentage within the group.

\subsection{Sad moments as a life lesson}

The main broad category of "Life lesson" are formed by small categories such as life lesson, life experience, finds meaning in life relatedness, life disparity, accept reality, and lastly as a valuable lesson. The concept of life lesson rotates around the importance of remaining positive. Sad moments are not defined as an obstacle; instead it is seen as an opportunity to learn. People, who see their sad moments as a form of life lesson, tend to rise from sadness faster than others (National Network for Family Resiliency, Children, Youth and Families Network, 
Putri, A. K., Prawitasari, J. E., Hakim, M. A., Yuniarti, K. W., \& Kim, U.

1995). They are able to perceive valuable lessons out of the hardship that was thrown at them. The types of people who view sad moments as a life lesson, mainly sees that there is always a silver line behind their sad and problematic moments. Some of the statements that best describe this category are; "It becomes a lesson about the meaning of life" and "It helps me learn about many things in life, and that, I should be grateful of".

\subsection{Sad moment as disruption}

"Disruption" category involves smaller categories such as annoying, hurt, diminishing spirit, caused disturbance, cause loneliness. Disruption is the opposite way of thinking positively. Any form of sad moments or stress is seen as merely a disruption within their life. They mainly view the causes of their sad moments externally, as an example, those who view that sad moment caused loneliness is because they view others as leaving him behind and thus loneliness appears. They do not blame themselves as the cause of those moments; they place themselves as victims of that sad situation. Several statements that describes these moments are "It causes me pain that might never have a cure", "It completely broke my heart!!", and "The meaning behind it is nothing but a sad, annoying, and heartbreaking moment".

\subsection{Sad moment as self-reflection}

Self Reflection category consists of an awareness to be careful, self-awareness, self-improvement, an awareness of self- relation. People who view sad moments as self-reflection cope through sad moments by reflecting those problems on themselves. They tend to look within, rather than outward. They do not blame others of the problems they face. In contrast, they view that those problems come because they caused it themselves. In other words, their sadness coping system is to make self-improvement. It gives them a sense of satisfaction when they are able to assure that these heavy situations will be able to be avoided by fixing their behavior that might have caused it. Some of the statements that are included within this category are "It makes me into a better person, because it means there is something that I must fix" and "It shows that I'm not trustworthy yet, so I still have to introspect myself'.

\subsection{Sad moment as a source of motivation}

The category of "Motivation" includes smaller categories which are new motivation and stronger/tougher. Motivation is one of the key concepts in every aspect of emotion. Motivation keeps people from plummeting in a terminal state of sadness. Similar to viewing sad moments as a life lesson, they both have a positive approach toward a problem. Some of the statements that best describe this category are "It shows that I have to keep trying!" and "I can't give up now".

\subsection{Sad moment as life's obstacles}

The main category of Life's obstacles are formed by small categories such as viewing sadness as failure, life's obstacles, pressures of life, and lastly as a time when they lose someone. They immerse themselves with other people in order to seek security as well as support. Another important aspect that must be considered is that these people see the causes of their sad moment as an external cause rather than internal. Some of the statements that describe this category are "It was an obstacle that destroyed my life" and "It means that I've lost an important person..."

\subsection{Sad moment as a memorable moment}

An interesting definition that came from several respondents was that they view sad moment as a memorable moment which consists of either as a very meaningful event, an unforgettable moment, or as an unexpected turn of event. Some of the statements from this category are "It meant a lot, because without it I would never have felt what sadness is like" and "It was a memory that I'd never forget". 
The second last category is the "spiritual lesson" which is combined from spiritual and learns sincerity in small categories. People within this category have a very holistic approach towards coping in their problems. They seek support and comfort from God. Increasing their praying times and being sincere to others are some of the ways to cope through their sad moments. They tend to view sad moment as a trial that was given to them, and thus becomes a spiritual lesson. These statements are example of the response from this category, "It is a sign from God that I still haven't discovered my real happiness, when I'm sad God shows me that I have many things to hold on to" and "It is destiny".

\subsection{Others}

The last main category that was originally written was "Others"; it contains irrelevant, meaningless, as well as blank answers that were not able to be processed within the data analysis due to its lack of relevancy towards the research. Overall, the results of the cross tabulation between male and female adolescents showed that there are different tendency between their perceptions on sadness. Compared to males, females mainly perceive sadness as a form of life-lesson (males $=22.9 \%$ and females $=30.4 \%$ ). However, in terms of viewing sadness as a disruption male adolescent scores higher than females by $1.8 \%$ (males $=15.4 \%$ and females $=13.6 \%$ ). The third highest category which is self-reflection is also seen more by females (males $=11.2 \%$ and females $=$ $13.9 \%)$.

\section{Discussions}

The present study examined the underlying concept of Indonesian male and females' perception on sadness Result showed that adolescents view sadness as one of 7 main categories, life lesson, disruption, self-reflection, motivation, life obstacles, memorable moments, and lastly as a spiritual lesson. In general, these categories can be divided into 2 main approaches which are the positive approach, containing sad moment as life lesson, self reflection, motivation, and lastly as a spiritual lesson, and the negative approach which are viewing sad moment as a disruption, life's obstacle, and memorable moment. The concept of positive approaches lay on the notion of resilience. Those who view sad moment as a positive approach tend to have high resilience. Resilient behavior is especially critical for vulnerable children and families, especially for adolescent who are very unstable. Resilience is defined as the ability to overcome or minimize the impact of adversity, or stress (Gerard \& Buehler, 2004). It is the ability to bounce back from crisis that may cause sad moments (National Network for Family Resiliency, Children, Youth and Families Network, 1995). Further it was stated that resilience is displayed in individuals as optimism, resourcefulness, and determination. This correlates with the findings, that categories that are seen as optimistic, as an example is viewing sad moment as a life lesson, would have develop higher resilience.The prospect of optimism relates to all the positive approach, while the notion of determination relates to viewing sadness as a source of motivation. Based on the result it is clear that Indonesian adolescent mainly view sad moments with a positive approach (73\%), with only $23 \%$ of them viewing it through a negative approach which indicated a high level of resilience. It is thus important to explore the factors that influence the development of said resilience.

Many researchers have suggested that adolescents' race/culture/ethnicity has a significant influence on how they deal with adverse circumstances (Arrington \& Wilson, 2000; Weaver, 2010). Furthermore, Sue and Sue (2003) noted that an individual's capability to adapt is largely influenced by their cultural background and worldview. According to Sue and Sue (2003), "worldviews are - composed of our attitudes, values, opinions, and concepts and affect how we think, define events, make decisions, and behave". It supports the idea that emotions are always situated and rooted in specific cultural contexts. Accordingly, they are influenced with many cultural meanings (Kitayama, Mesquita, \& Karasawa, 2004; Uchida, Norasakkunkit, \& Kitayama, 2004). It is also noted that this cultural influence later creates specific lifestyle. Uchida et al. (2004) stated that "These meanings and practices constitute local 'ways of life', which as a whole are defined as culture". This explained 
Putri, A. K., Prawitasari, J. E., Hakim, M. A., Yuniarti, K. W., \& Kim, U.

why most Indonesian adolescents were able to take positive means from their sad moments.

Asian countries are very distinct from the West. Wherein westerns tend to blame others or external factors in order to preserve one's self-esteem, Asians often take a more self-critical approach by blaming themselves focusing the causes of problems internally (Kitayama, Takagi, \& Matsumoto, 1995; Uchida \& Kitayama, 2009). This seems to be the self-depreciative attribution pattern of Asians. It is likely to be part of an adaptive process of self-improvement whereby people are motivated to find solution for their difficulties. The cultural norms that shaped people from the very beginning that they should feel more reluctant is what cause most adolescents, especially females, to view sad moment as a form of self-reflection and later as motivation. Both female and male adolescents are influenced by this cultural factor due to the intensity of it ever since they were a child. In general there is no difference in the type of category between male and female adolescents. Nevertheless, the only difference was the percentage that differs among them. This probably can be explained by the stereotypical gender-based emotions that are expected from males and females from the community or family.

Males are perceived to be stronger than females, and is less likely to show real emotions, especially those that makes them look weak (Aldrich \& Tenenbaum, 2006). In fact, ever since we're little our parents style of talking shapes our emotional expressiveness which also contributes to how we develop our coping strategy (Aldrich \& Tenenbaum, 2006). Further, the female adolescent was found to be more expressive in showing their sadness, while male adolescents, in contradiction towards Aldrich and Tenenbaum's hypothesis, and shows more references on sadness than did girls. This was due to the fact that from childhood, boys were trained to hide and cope with their sadness on their own. They tend to neglect their problems, and thus they have more reference on sadness though they do not express it so. This creates further problems because these unresolved problems, which later becomes the basis of viewing sad moment as memorable moments, often cause adolescents to be depressive. Also, neglected sad moment may cause adolescent to be in a state of rumination, which is a maladaptive cognitive process involving repetitive thoughts that are intrusive and aversive (Peled \& Moretti, 2007). Further it was explained that the level of rumination experienced by female adolescents are higher than males. Rumination was later found to be a critical factor towards the development of depression (Peled \& Moretti, 2007). This supports the notion that the negative approach of viewing sad moments as a disruption, memorable moment, as well as a life's obstacles does create negative impacts toward the wellbeing of the adolescents. They mainly focused on unresolved problems and stresses that they deem uncontrollable. For these reasons, they have lower resilience than those that are optimist.

Based on this result, it is possible to view the relation of why male adolescents tend to view sad moments as more of a disruption than as a self-reflection. As they are not used to be expressive they tend to neglect their problems, leaving it unresolved. This becomes the basis of how they view sad moments as a memorable moment, indicating their inability to let it go. It also explains why they view sad moments as a disruption. However, it should not be forgotten that they too have high frequency to self reflect. This is once again based on the cultural influences that are very strong in promoting social openness and optimism. Overall the findings suggest that some of Indonesian adolescents' perception on sadness supported several western theories while others are very conceptually based, such as those influenced by their culture.

\section{Conclusion}

Based on the result of the study using the indigenous approach, several perspectives on sad moments by Indonesian male and female adolescent were achieved. These perspectives are: Sad moment as life lesson, as disruption, self-reflection, life's obstacles, motivation, memorable moments, as spiritual lesson, and lastly others. These perceptions were then divided into 2 main approaches, the positive approach and the negative approach. Based on the statistical result, there are no significant differences in the perception of sad moments between Indonesian male and female adolescent. Results showed that Indonesian male and female adolescents tend to view their sad moments in a positive approach, in which they view it most as a life lesson. Result merely differs in the percentage of each category though the sequence from the less to the most frequent perception in general 
Sadness as perceived by Indonesian male and female adolescents

is similar. As an example female adolescent have higher percentage in most categories, however they view sad moment as self reflection as second highest while male adolescent view disruption as second highest.

In conclusion, both Indonesian male and female adolescent mainly took a positive perception on sadness, which is as a life lesson. Further, positively both Indonesian male and female adolescents perceive sadness as a life lesson, however negatively they view it mostly as a disruption. The intensity of these perceptions however, differs across gender. Additionally, it was also found that Indonesian adolescents' perception on sadness supported several western theories while other responses were found to be very conceptually based and specific to their cultural background.

\section{References:}

Aldrich, N., \& Tenenbaum, H. (2006). Sadness, anger, and frustration: Gendered patterns in early adolescents' and their parents' emotion talk. Sex Roles, 55, 775-785. doi:10.1007/s11199-006-9131-y <http://dx.doi.org/10.1007/s11199-006-9131-y>

Algoe, S. B., Buswell, B. N., \& DeLamater, J. D. (2000). Gender and job status as contextual cues for the interpretation of facial expression of emotion. Sex Roles, 42, 183-208. doi:10.1023/A:1007087106159 $<$ http://dx.doi.org/10.1023/A:1007087106159>

Arrington, E. G., \& Wilson, M. N. (2000). A re-examination of risk and resilience during adolescence: Incorporating culture and diversity. Journal of Child and Family Studies, 9(2), 221-230. doi:10.1023/A:1009423106045 <http://dx.doi.org/10.1023/A:1009423106045>

Brinol, P., Barden J., \& Petty, R. (2007). Happiness versus sadness as a determinant of thought confidence in persuasion: A self validation analysis. Journal of Personality and Social Psychology, 93, 711-727. doi:10.1037/0022-3514.93.5.711 < http://dx.doi.org/10.1037/0022-3514.93.5.711>

Brody, L. R., \& Hall, J. A. (2000). Gender, emotion, and expression. In M. Lewis \& J. M. Haviland-Jones (Eds.), Handbook of emotions (2nd ed.) (pp. 338-349). New York: Guilford Press.

Campos, J. J., Campos, R. G., \& Barrett, K. C. (1989). Emergent themes in the study of emotional development and emotion regulation. Developmental Psychology, 25(3), 394-402. doi:10.1037/0012-1649.25.3.394 <http://dx.doi.org/10.1037/0012-1649.25.3.394>

Chaplin, T. (2006). Anger, happiness and sadness: Associations with depressive symptoms in late adolescence. Journal of Youth and Adolescence, 35, 977-986. doi:10.1007/s10964-006-9033-x $<$ http://dx.doi.org/10.1007/s10964-006-9033-x>

Durand, V., \& Barlow, D. (2006). Intisari: Psikologi abnormal (4th ed). [In Indonesian] Pustaka Pelajar.

Ellsworth, P. C., \& Smith, C. A. (1988). From appraisal to emotion: Differences among unpleasant feelings. Motivation and Emotion, 12, 271-302. doi:10.1007/BF00993115 $<$ http://dx.doi.org/10.1007/BF00993115>

Fischer, A. H. (Ed.). (2000). Gender and emotion: Social psychological perspectives. Cambridge, UK: Cambridge University Press.

Fischer, A. H., Rodriguez Mosquera, P. M., Van Vianen, A. E. M., \& Manstead, A. S. R. (2004). Gender and culture differences in emotion, Emotion, 4(1), 87-94. doi:10.1037/1528-3542.4.1.87 $<$ http://dx.doi.org/10.1037/1528-3542.4.1.87>

Garaigordobil, M., Maganto, C., Perez, J., \& Sansinenea, E. (2009). Gender differences in socio-emotional factors during adolescence and effects of a violence prevention program. Journal of Adolescent Health, 44(5), 468-477. doi:10.1016/j.jadohealth.2008.09.014 $<$ http://dx.doi.org/10.1016/j.jadohealth.2008.09.014>

Gerard, J., \& Buehler, C., (2004). Cumulative environmental risk and youth maladjusment: The role of youth attributes. Child Development, 75, 1832-1849. doi:10.1111/j.1467-8624.2004.00820.x $<$ http://dx.doi.org/10.1111/j.1467-8624.2004.00820.x >

Karnani, H., \& Pomm, H., (2006). Screening for adolescent depression and anxiety in the primary care environment: Calming the storm within. Northeast Florida Medicine, 57, 41-46. 
Putri, A. K., Prawitasari, J. E., Hakim, M. A., Yuniarti, K. W., \& Kim, U.

Kasch, K. L., Rottenberg, J., Arnow, B. A., \& Gotlib, I. H. (2002). Behavioral activation and inhibition systems and the severity and course of depression. Journal of Abnormal Psychology, 111, 589-597. doi:10.1037/0021-843X.111.4.589 <http://dx.doi.org/10.1037/0021-843X.111.4.589>

Kim, U., \& Berry, J. (1993). Introduction. Indigenous psychologies. Research and experience in cultural context. (Vol. 17), Cross-Cultural Research and Methodology Series. Newbury Park, CA: Sage.

Kim, U., \& Park, Y. S. (2006). The scientific foundation of indigenous and cultural psychology: The Transactional approach. In U. Kim, K. S. Yang, \& K. K. Hwang (Eds.), Indigenous and cultural psychology, understanding people in context (pp. 27-48). New York: Springer. $<$ http://dx.doi.org/10.1007/0-387-28662-4_2>

Kitayama, S., Takagi, H., \& Matsumoto, H. (1995). Cultural constructions of happiness: Theory and empirical evidence. In Uchida, Y., Norasakkunkit, V., \& Kitayama, S. (Eds). Journal of Happiness Studies, 5 , 223-239.

Kitayama, S., Mesquita, B., \& Karasawa, M. (2004). The emotional basis of independent and interdependent selves: Socially disengaging and Engaging emotions in the US and Japan. Unpublished manuscript, University of Michigan.

Maccoby, E. E. (2002). Gender and group process: A developmental perspective. Current Directions in Psychological Science, 11, 54-58. doi:10.1111/1467-8721.00167 $<$ http://dx.doi.org/10.1111/1467-8721.00167>

National Network for Family Resiliency Children, Youth and Families Network. (1995). Family resiliency: building strengths to meet life's challenges. Retrieved from http://www.extension.iastate.edu/publications/edc53.pdf

Parrish, C., \& Zeman, J., (2009). Relations among sadness regulation, peer acceptance, and social functioning in early adolescence. The Role of Gender, 20(1), 135-153. doi:10.1111/j.1467-9507.2009.00568.x $<$ http://dx.doi.org/10.1111/j.1467-9507.2009.00568.x>

Peled, M., \& Moretti, M. (2007). Rumination on anger and sadness in adolescence: Fueling of fury and deepening of despair. Journal of Clinical Child and Adolescent Psychology, 36, 66-75.

Plant, E., Kristen, C., \& Smith, G. (2004). The influence of gender and social role on the interpretation of facial expression. Sex Roles, 51, 187-196. doi:10.1023/B:SERS.0000037762.10349.13 <http://dx.doi.org/10.1023/B:SERS.0000037762.10349.13>

Rivers, S., Brackett, A., Katulak, N., \& Salovey, P. (2007). Regulating anger and sadness: An exploration of discrete emotions in emotion regulation. Journal of Happiness Studies, 8, 393-427. doi:10.1007/s10902-006-9017-2 <http://dx.doi.org/10.1007/s10902-006-9017-2>

Sue, D. W., \& Sue, D. (2003). Counseling the culturally diverse: Theory and Practice (4th ed). NY: Wiley \& Son

Sullivan, T., Helms, S., Kliewer, W., \& Goodman, K. (2008). Associations between sadness and anger regulation coping, emotional expression, and physical and relational aggression among urban adolescents. Social Development, 9, 30-51. doi:10.1111/j.1467-9507.2008.00531.x $<$ http://dx.doi.org/10.1111/j.1467-9507.2008.00531.x>

Tiedens, L. Z. (2001), Anger and advancement versus sadness and subjugation: The effect of negative emotion expressions on social status conferral, Journal of Personality and Social Psychology, 80, 86-94. doi:10.1037/0022-3514.80.1.86 <http://dx.doi.org/10.1037/0022-3514.80.1.86>

Tiedens, L. Z., Ellsworth, P. C., \& Mesquita, B. (2000). Stereotypes about sentiments and status: Emotional expectations for high and low-status group members. Personality and Social Psychology Bulletin, 26, 560-574. doi:10.1177/0146167200267004 <http://dx.doi.org/10.1177/0146167200267004>

Uchida, Y., \& Kitayama, S. (2009). Happiness and unhappiness in East and West: Themes and variations. Emotion, 4, 441-456. doi:10.1037/a0015634 <http://dx.doi.org/10.1037/a0015634>

Uchida, Y., Norasakkunkit, V., \& Kitayama, S. (2004). Cultural constructions of happiness: Theory and empirical evidence. Journal of Happiness Studies, 5, 223-239. doi:10.1007/s10902-004-8785-9 $<$ http://dx.doi.org/10.1007/s10902-004-8785-9>

Weaver, D. (2010). The relationship between cultural/ethnic identity and individual protective factors of academic resilience. Retrieved from http://counselingoutfitters.com/vistas/vistas10/Article_67.pdf 